\title{
Caracterização dos textos de divulgação científica inseridos em livros didáticos de biologia
}

\section{Description of popular science texts inserted in biology textbooks}

\author{
${ }^{1}$ Pedro Henrique Ribeiro de Souza pedrohrsouza@hotmail.com \\ ${ }^{2}$ Marcelo Borges Rocha
}

\section{RESUMO}

Textos de Divulgação Científica (TDC) são utilizados no Ensino de Ciências por contextualizar o conteúdo curricular e relacioná-lo ao cotidiano dos alunos. Os livros didáticos de Ciências apresentam TDC, em sua maioria, adaptados, o que pode interferir no seu conteúdo original. Este trabalho identificou os TDC em nove coleções didáticas de Biologia do Ensino Médio, aprovadas pelo PNLD/2015. Foram encontrados 398 textos, destacando-se a coleção de Favaretto. A maior parte dos textos eram adaptados e estavam em capítulos de Ecologia, Zoologia e Evolução. Os livros utilizaram textos de fontes diversas, porém destacam-se jornais e revistas de DC, como a Ciência Hoje, o que indica a opção por textos com linguagem mais acessível aos alunos. Atenta-se para a importância de analisar estes textos e entender que alterações foram realizadas na inserção dos mesmos nos livros didáticos.

Palavras-chave: Divulgação científica. Livro didático. Ensino de biologia.

\section{ABSTRACT}

Popularisation of Science texts are used in Science Education for contextualizing the curriculum content and relating it to the daily lives of students. Textbooks insert popular science texts, mostly adapted, which can interfere in its original content. This work identified the popular science texts in nine teaching collections of high school Biology, approved by PNLD/2015. 398 texts were found, highlighting the collection of Favaretto. Most of them were adapted and were in Ecology, Zoology and Evolution chapters. The books used texts from various sources, but stand out newspapers and popular science magazines, such as Ciência Hoje, which indicates the choice of more accessible texts to the students language. It is important to analyze these texts and understand what changes were made in inserting them in textbooks.

Keywords: Scientific dissemination. Textbooks. Biology teaching.

\footnotetext{
1 Centro Federal de Educação Tecnológica Celso Suckow da Fonseca - CEFET/RJ Colégio Pedro II 


\section{INTRODUÇÃO}

O principal objetivo da Divulgação Científica (DC) é garantir o acesso da população aos conhecimentos científicos e tecnológicos, considerando a relevância dos impactos da ciência e da tecnologia na sociedade e no ambiente. Presente em jornais, revistas, rádio, TV, internet, redes sociais, livros, filmes, documentários, museus e centros de ciência, dentre outros espaços, a DC se torna cada vez mais valorizada, o que justifica a importância da problematização, ampliação e aperfeiçoamento das atividades de DC, permitindo a democratização dos conhecimentos científicos.

Para Loureiro (2003, p. 90 e 91), a DC está “voltada à circulação de informação em ciência e tecnologia para o público em geral”, o que implica no "emprego de técnicas de recodificação de linguagem da informação científica e tecnológica objetivando atingir o público em geral e utilizando diferentes meios de comunicação de massa”. Para Bueno (2010, p. 2), na DC o público "não tem, obrigatoriamente, formação técnico-científica que lhe permita, sem maior esforço, decodificar um jargão técnico ou compreender conceitos que respaldam o processo singular de circulação de informações especializadas”. Para este autor, a DC requer processos de decodificação ou de recodificação, utilizando recursos, como metáforas e ilustrações, com o objetivo de facilitar o seu entendimento pelo público leigo. Porém, isto poderia penalizar a precisão das informações, o que levaria a leituras equivocadas e incompletas.

Orlandi (2001) aponta para o caráter híbrido do discurso da DC, constituído pela união dos discursos científico, jornalístico e cotidiano, ocorrendo uma "metaforização" dos discursos científico e jornalístico na relação com o cotidiano, o que é necessário para reduzir o uso excessivo de terminologias científicas. Authier (1982, p. 35) analisa a DC através da Análise de Discurso de linha francesa e argumenta que, ao divulgar a ciência, ocorre a "reformulação de um discurso-fonte (D1) em um discurso segundo (D2)”, expressões comuns na área da comunicação que esclarecem as diferenças entre o público alvo e o que transmite o discurso científico. Zamboni (1997, p. 11) reconhece que a DC é um gênero de discurso específico, "resultado de um efetivo trabalho de formulação discursiva, no qual se revela uma ação comunicativa que parte de um ‘outro’ discurso e se dirige para 'outro’ destinatário”. A autora também observa uma "superposição de traços de cientificidade, laicidade e didaticidade, que se deixam mostrar, em graus variados, na superfície dos textos” (ZAMBONI, 2001, p. 96), onde os traços de cientificidade são típicos do discurso científico, os de laicidade são inerentes ao discurso cotidiano e os de didaticidade são próprios do discurso didático, como recapitulações e explicações.

Gonçalves (2013) reforça a relevância da DC, no atual contexto de impactos científicos e tecnológicos na sociedade, a DC é profundamente exigida, o que justifica uma análise mais aprofundada das pesquisas nesta área temática. A autora destaca a função social da DC, que busca entender, explicar e interagir com o leitor a respeito dos temas científicos e tecnológicos de impacto, assegurando às pessoas a consciência de sua cidadania e a participação nos destinos da nação e do mundo.

O estudo desse segmento, na perspectiva discursiva, leva-nos a entender que não se trata de uma atividade neutra, nem de um jornalismo totalmente objetivo, de forma que revistas com perfis editoriais diferenciados oferecem tratamentos distintos às temáticas abordadas e relacionam-se de formas distintas com o seu público. Pode-se, assim, propor que se trata de diferentes discursos da Divulgação Científica, ou de diferentes gêneros ou subgêneros no mesmo segmento midiático (GONÇALVES, 2013, p. 212).

A utilização de textos de DC no Ensino de Ciências se justifica por incluir os alunos em debates sobre temas específicos da ciência que podem impactar suas vidas e trabalho, como transgênicos, células tronco, mudanças climáticas, energias renováveis, dentre outros. Portanto, sua utilização é recomendada pelos Parâmetros Curriculares Nacionais (PCNs), enquanto fontes alternativas de conhecimento (BRASIL, 2000), e por outros autores na área de pesquisa em Ensino de Ciências (e.g. MARTINS et al., 2001; 2004; Autor X1). Além de representar uma forma de contextualizar os conhecimentos científicos presentes nos conteúdos disciplinares, os textos de DC contribuem para o incentivo à prática da leitura, familiarizando-se com terminologias e conceitos científicos e entendendo a natureza da atividade científica. 
No entanto, a linha editorial das diferentes vertentes de publicações de DC não possuem o objetivo de tornar os leitores especializados em uma determinada área científica, ou seja, sem a mesma finalidade pedagógica dos livros didáticos (GRILLO, et al., 2004; Autor X1). Logo é fundamental a participação dos professores na seleção e possível adaptação destes textos, entendendo sua pertinência e adequação a diferentes contextos.

No universo de produções científicas que realizam a ponte entre DC e Ensino de Ciências, destacam-se trabalhos que investigam a forma como textos de DC são reelaborados ao serem inseridos em livros didáticos (MARTINS et al., 2001; MARTINS \&; DAMASCENO, 2002; NASCIMENTO, 2005; Autores X2) ou ao serem aplicados em sala de aula, em atividades realizadas com professores em formação (MARTINS et al., 2004; NASCIMENTO, 2008). Há trabalhos que buscaram a opinião de professores sobre a forma como estes usam publicações de divulgação científica em suas aulas (Autor X1; GOMES et al., 2012). Outros trabalhos realizaram levantamentos das produções que tratam de DC em sala de aula apresentadas nas edições do Encontro Nacional de Pesquisa em Educação em Ciências (ENPEC) (PUIATI et al., 2009; FERREIRA \&; QUEIROZ, 2012a) ou em periódicos e outras produções acadêmicas (NASCIMENTO \& REZENDE-JR., 2010; Autores X3). Existem também artigos na literatura que visam analisar artigos de DC, de acordo com certas temáticas, como Genética (GOLDBACH, 2005; GOLDBACH \& EL-HANI, 2008), Evolução (KEMPER, 2010), Química (FERREIRA \& QUEIROZ, 2012b) e Sistemática Filogenética (Autores X4).

O objetivo do presente trabalho é realizar uma caracterização dos textos de DC presentes nas coleções de livros didáticos de Biologia do Ensino Médio, observando em que áreas temáticas da Biologia se enquadram, em que capítulos e unidades foram inseridos, de que maneira ocorreu esta inserção, que recursos visuais estavam presentes, de que fontes midiáticas foram extraídos e qual a formação acadêmica e a ocupação profissional dos autores. Para tal, foram utilizadas as obras recomendadas pelo último Programa Nacional do Livro Didático (BRASIL, 2014), com vigência a partir de 2015.

\section{TEXTOS DE DIVULGAÇÃO CIENTÍFICA EM LIVROS DIDÁTICOS}

Com o intuito de tornar as coleções mais atrativas e contextualizadas, os autores de livros didáticos incrementam suas obras com maior diversidade de fontes de informação, além da parte textual na qual desenvolvem o conteúdo. Imagens, infográficos, exercícios e uma diversa gama de textos escritos por outros autores ganham cada vez mais espaço nestas coleções. É possível encontrar, portanto, textos de DC espalhados nestas obras, sejam eles colocados como motivadores ou como forma de contextualização e de complementação dos conteúdos detalhados nos diferentes capítulos. Porém, deve-se procurar entender por que e de que maneira estes textos foram selecionados e adaptados ao serem incorporados nos livros didáticos.

Martins e Damasceno (2002) analisaram seis coleções de livros didáticos de Ciências e constataram que a maioria dos textos de DC encontrados (84\%) eram provenientes de jornais e revistas de divulgação e que grande parte destes textos (65\%) sofreu algum tipo de adaptação para a sua inclusão no livro didático.

Nascimento (2005) identificou a presença de textos de DC adaptados nos livros, analisando a forma como um texto de DC sobre clonagem foi inserido em um livro didático de ciências, sofrendo operações de reelaboração discursiva. O estudo revelou que o texto original não estabelece conexões com as demais partes do livro, mantendo as principais características do discurso da divulgação.

Galieta (2013) comparou, à luz da Análise de Discurso de linha francesa, um texto de DC com um texto presente em um livro didático de Ciências do Ensino Fundamental, que abordava o mesmo assunto do texto de DC, percebendo uma diferença significativa entre os discursos do texto didático, marcado pelo discurso científico e pedagógico, e o do texto de DC, que se relaciona mais com o discurso cotidiano, lançando mão do discurso científico quando necessita de maiores explicações científicas em seu texto. 
Também com uma análise discursiva, Rocha (2012), Cavalcante Filho e Torga (2013) e Silva (2013) destacam a importância da leitura e elaboração de artigos de DC em livros didáticos de Língua Portuguesa de Ensino Médio. Em comum, estes trabalhos indicam uma crescente utilização destes textos no ensino para que os alunos entendam de que maneira os divulgadores da ciência, sejam eles cientistas ou jornalistas, estruturam seus textos e que discursos dialogam neste processo.

Autores X2 analisaram as alterações sofridas por um texto de divulgação ao ser inserido em livro didático de ciências. O texto original foi amplamente reduzido na passagem para um livro de Ciências do $6^{\circ}$ ano do Ensino Fundamental. Identificou-se, nesta transferência, processos de reelaboração discursiva, como substituição, adição, eliminação e reordenação, além de mudanças na linguagem do texto e na própria visão da natureza da ciência, de tal forma a se adequar ao programa curricular da série e à faixa etária dos alunos.

\section{METODOLOGIA}

As coleções de livros didáticos de Biologia do Ensino Médio foram selecionadas a partir do Programa Nacional do Livro Didático (PNLD), cujo guia informa em resenhas os principais aspectos de cada obra de forma crítica (BRASIL, 2014). Cada coleção é composta por três livros didáticos, cada um destinado a uma determinada série do Ensino Médio. Dentre estas nove coleções, destacam-se os principais autores de livros didáticos de Biologia para o Ensino Médio, como Sônia Lopes e Sérgio Rosso; César da Silva Jr., Sezar Sasson e Nélson Caldini; José M. Amabis e Gilberto Martho; Sérgio Linhares e Fernando Gewandsznajder; Nélio Bizzo, dentre outros, reconhecidos pela notável preferência e utilização por muitos professores do componente curricular.

Ao observar os sumários das coleções, é importante destacar que as coleções didáticas não seguem a mesma sequência das diferentes áreas temáticas da Biologia, o que indica uma diversidade de abordagens deste componente curricular ao longo das três séries do Ensino Médio. Enquanto certos autores mantém a organização tradicional dos livros didáticos, iniciando na Biologia Celular e encerrando em Ecologia, alguns autores aderem a uma divisão que primeiro contextualiza o ambiente onde a vida se insere para depois explorar os outros temas biológicos. A tabela 1 apresenta as principais informações sobre cada livro didático e uma codificação das obras, de modo a facilitar a sua referenciação ao longo deste artigo.

Tabela 1 - Principais informações a respeito das nove coleções didáticas utilizadas.

\begin{tabular}{lllll}
\hline Código & Coleção & Autores & Editora & Edição \\
\hline L01 & Bio & Sônia Lopes e Sérgio Rosso & Saraiva & $2^{\text {a de } 2013}$ \\
\hline L02 & Biologia & $\begin{array}{l}\text { César da Silva Júnior, Sezar } \\
\text { Sasson e Nélson Caldini Júnior }\end{array}$ & Saraiva & $1^{\text {a }}$ de 2013 \\
\hline L03 & Biologia & Vivian Lavander Mendonça & AJS & $2^{\text {a de } 2013}$ \\
\hline L04 & Biologia em contexto & $\begin{array}{l}\text { José Mariano Amabis e Gilberto } \\
\text { Rodrigues Martho }\end{array}$ & Moderna & $1^{\text {a de } 2013}$ \\
\hline L05 & Biologia hoje & $\begin{array}{l}\text { Sérgio Linhares e Fernando } \\
\text { Gewandsznajder }\end{array}$ & Ática & $2^{\text {a de } 2013}$ \\
\hline L07 & Biologia Unidade e Diversidade & José Arnaldo Favaretto & Saraiva & $1^{\text {a de } 2013}$ \\
\hline L08 & Conexões em Biologia & Rita Helena Bröckelmann & Moderna & $1^{\text {a de } 2013}$ \\
\hline L09 & Ser Protagonista - Biologia & $\begin{array}{l}\text { Márcia Regina Takeuchi e } \\
\text { Tereza Costa Osorio }\end{array}$ & Ática & $2^{\text {a de } 2013}$ \\
\hline
\end{tabular}

Fonte: autores. 
O acesso às coleções analisadas se deu por meio de sua disponibilização pelas próprias editoras durante o processo de escolha dos livros didáticos em escolas públicas do Rio de Janeiro, no ano de 2014. Esta estratégia teve como intuito aproximar os professores das coleções, permitindo que os mesmos comparem as obras e decidam qual delas seria a mais adequada para a sua escola, ponderando fatores como a disposição dos temas nos capítulos dos livros, presença e qualidade de figuras, exercícios, experimentos e leituras complementares. Cabe ressaltar que algumas obras também possuem versão digital, na internet ou em CD-ROM, o que facilita a leitura em plataformas digitais, como computadores, notebooks e tablets.

A pesquisa se deu com a leitura minuciosa das coleções, buscando textos de DC inseridos nos diversos capítulos e unidades das coleções. Analisando-se os artigos de DC sob diferentes aspectos: a) em que área temática da Biologia (unidade ou capítulo) o texto foi encontrado; b) de que maneira o texto aparece: na forma de citação, sugestão ou recomendação de leitura, pequeno trecho, o texto adaptado ou editado, ou a presença do texto na íntegra; c) que recursos visuais o texto lança mão, sejam figuras, esquemas, gráficos ou tabelas; d) quais mídias (jornais, revistas, páginas da internet, etc.) serviram de fonte para estes textos; e e) qual a formação acadêmica e a ocupação profissional dos autores dos textos.

\section{RESULTADOS E DISCUSSÃO}

Foram encontrados 398 textos de DC nas sete coleções didáticas analisadas, estando a maior parte na coleção L06, que apresentou um total de 127 textos, seguida por L08 com 76 e L07 com 45 . Por outro lado, a coleção L05 utilizou apenas sete artigos de DC ao longo de seus três volumes. A média encontrada é de 44,22 textos por coleção, o que resulta em aproximadamente 15 textos por livro didático (considerando que cada coleção apresenta três volumes). O gráfico 1 compara as quantidades de textos de DC em cada coleção didática.

\section{Gráfico 1 - quantidade de textos de DC por coleção didática analisada.}

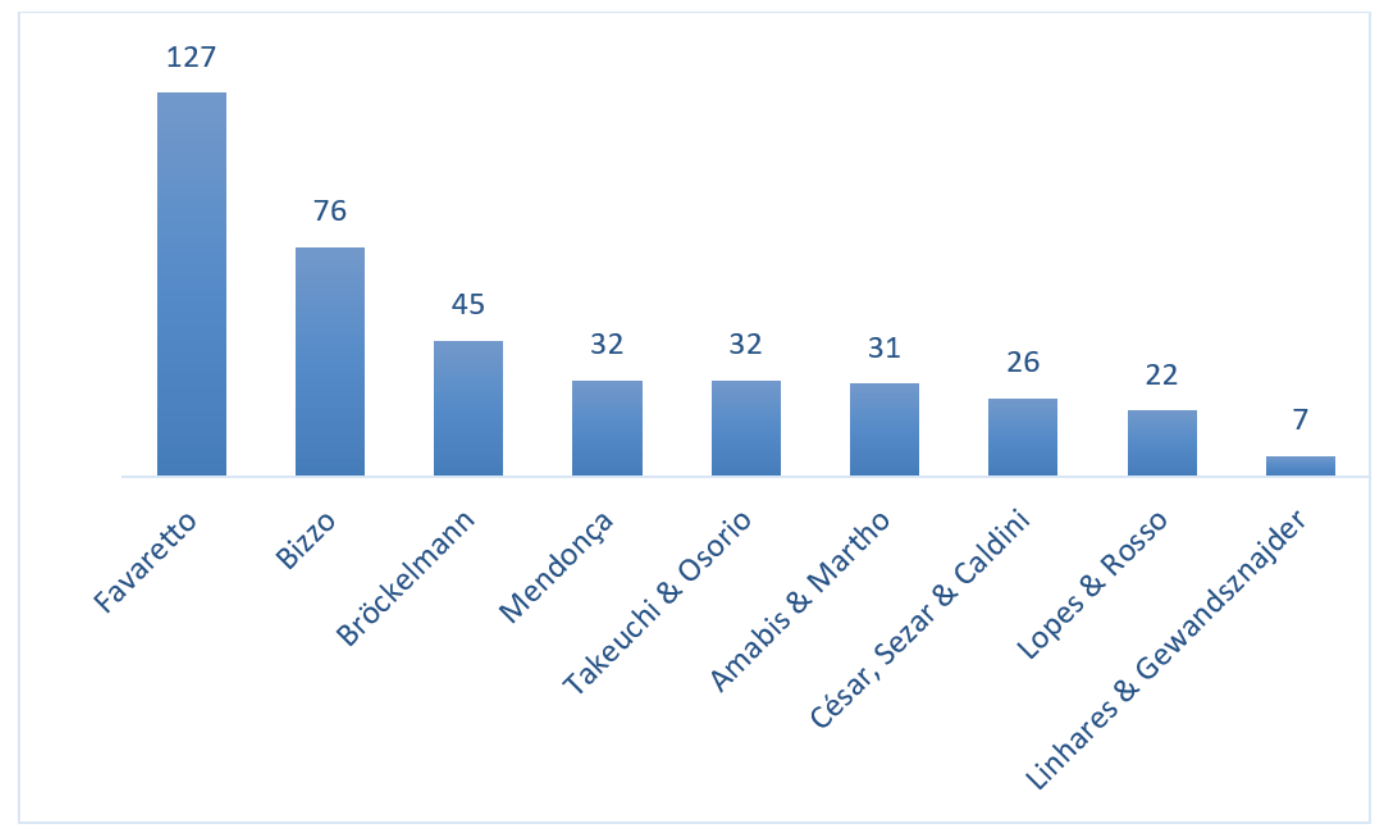

Fonte: autores. 
Estes resultados são coerentes com a posição dos autores de determinadas obras a respeito de materiais provenientes de DC. A coleção L06, que apresentou a maioria dos artigos, apresenta uma seção denominada “A Notícia”, onde inclui reportagens extraídas da mídia impressa e eletrônica. Já a coleção L07 recomenda a organização de um jornal de ciências em sala de aula, sugerindo as revistas Ciência Hoje, Pesquisa Fapesp e o site do Labjor como modelo. As coleções L03 e L09 recomendam livros, sites e revistas de DC ao final de cada volume, enquanto os livros da coleção L04 desenvolvem atividades de elaboração de resenhas críticas de artigos de DC. Em contrapartida, a coleção L05, possui uma seção intitulada "Seja crítico ao ler notícias!”, sugerindo um distanciamento com a DC, visto que foi a coleção que apresentou a menor quantidade de textos de DC.

A presença dos textos de DC em livros didáticos de Biologia revela uma preocupação dos autores destas coleções em contextualizar os conteúdos disciplinares, promovendo uma integração entre a ciência e o cotidiano do aluno, tal como indica Autor X1. No entanto, as coleções apresentam diferentes formas de inserir estes artigos, seja no que tange à área temática da Biologia com a qual o texto está mais relacionado ou ao grau de edição e adaptação que o mesmo sofre ao ser inserido no livro didático. Há de considerar que os textos de DC não são os únicos utilizados nas obras analisadas, podendo ser identificados artigos acadêmicos, destinados às revistas especializadas de disseminação científica, ou ainda textos de pesquisadores escritos especialmente para o livro didático, o que é comum na coleção de L01. Portanto, para esta pesquisa, tais escritos não foram considerados, pois utilizamos a concepção de DC apresentada por Bueno (2010), de que os textos de DC são destinados ao público geral e não a outros cientistas. É importante salientar que as coleções também recomendam outras formas de DC, como livros, filmes e sites.

Em relação à área temática da Biologia, a maior parte dos textos foi identificada em capítulos relativos à Ecologia (62), seguidos pelos de Zoologia (52) e de Evolução (35). No caso da Ecologia e da Evolução, que são temas integradores da diferentes áreas da Biologia, o montante de artigos sugere um grande volume de pesquisas nesta área. Isto se deve aos impactos ambientais de natureza antrópica, que afetam a vida das populações humanas, e às controvérsias e curiosidades geradas pelas pesquisas que tratam dos processos evolutivos. Quanto à Zoologia, pesam a grande quantidade de capítulos sobre o assunto e a curiosidade que este desperta, em especial com relação às matérias relativas a hábitos de vida dos animais, relações evolutivas e possíveis acidentes ou doenças ocasionadas por animais.

A área de Biotecnologia e Genética Molecular apresentou uma quantidade mediana de textos (21), a despeito de ser um campo de estudos de intenso crescimento e impacto na atualidade com a produção de novas tecnologias e produtos que influenciam o modo de vida da sociedade. Os temas "classificação dos seres vivos" e "natureza da ciência” obtiveram a menor quantidade de artigos (quatro para cada um), possivelmente por serem assuntos contemplados por apenas um capítulo por coleção. O gráfico 2 compara a quantidade de textos encontrados por área temática da Biologia. É importante ressaltar que esta tendência foi observada na maioria das coleções didáticas, não havendo, portanto, diferenças significativas na distribuição destes textos por área temática. 


\section{Gráfico 2 - quantidade de textos de DC por área temática da Biologia onde estavam inseridos nas coleções didáticas.}

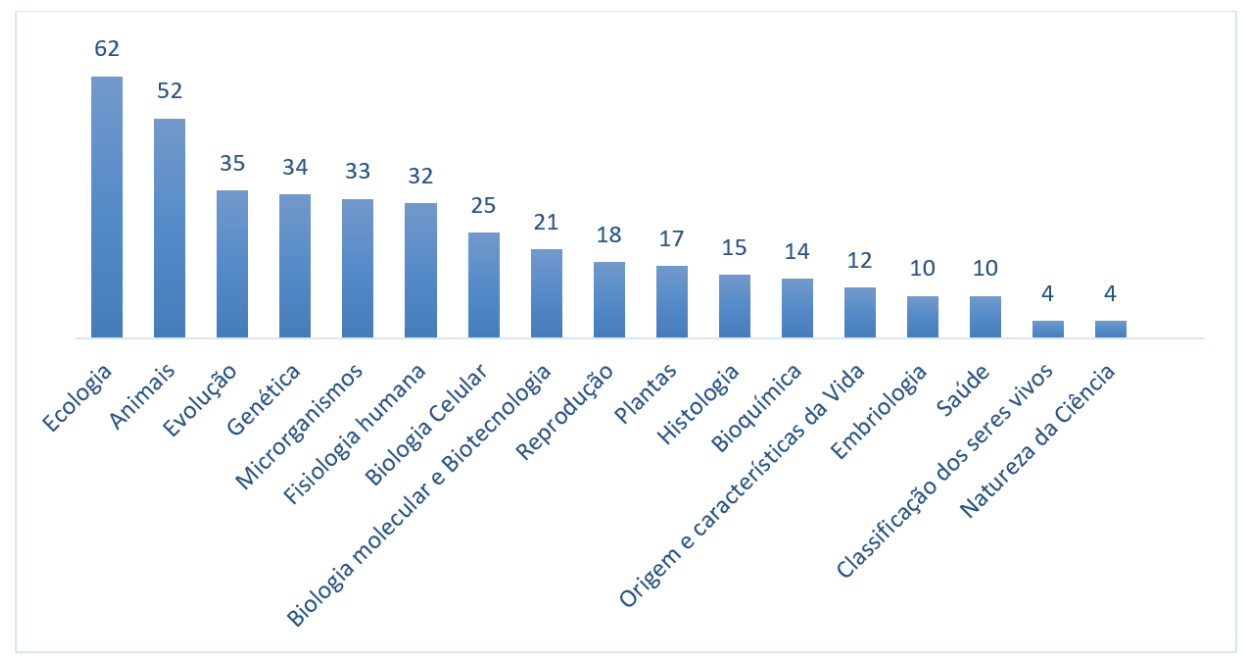

Fonte: autores.

Foram encontrados 159 textos que evidenciaram algum tipo de adaptação, como edição ou tradução de artigos em inglês, configurando a maior parte dos textos encontrados nas coleções L01, L02, L06, L07 e L09. Já as recomendações de leitura totalizam 85 ocorrências, sendo que 74 destas foram encontradas na coleção L08. Além destes, 58 textos não pareciam ter sofrido qualquer tipo de adaptação e 55 são trechos de artigos de DC, espalhados ao longo dos capítulos dos livros didáticos ou servindo a exercícios formulados pelos próprios autores, configurando a forma predominante da coleção de L04. Por último, estão as citações de artigos de DC, onde indica-se que dados destes artigos serviram de fonte para textos escritos pelos próprios autores das coleções, o que ocorreu na maior parte dos textos da coleção L03 e na totalidade dos encontrados na coleção L05. Foram excluídas da análise os trechos de artigos de DC em questões de vestibular ou do Enem, por não terem sido selecionados diretamente pelos autores das coleções. O gráfico 3 ilustra a forma como os textos de DC foram inseridos nos livros didáticos de Biologia.

Gráfico 3 - Forma dos textos de DC ao serem inseridos nos livros didáticos.

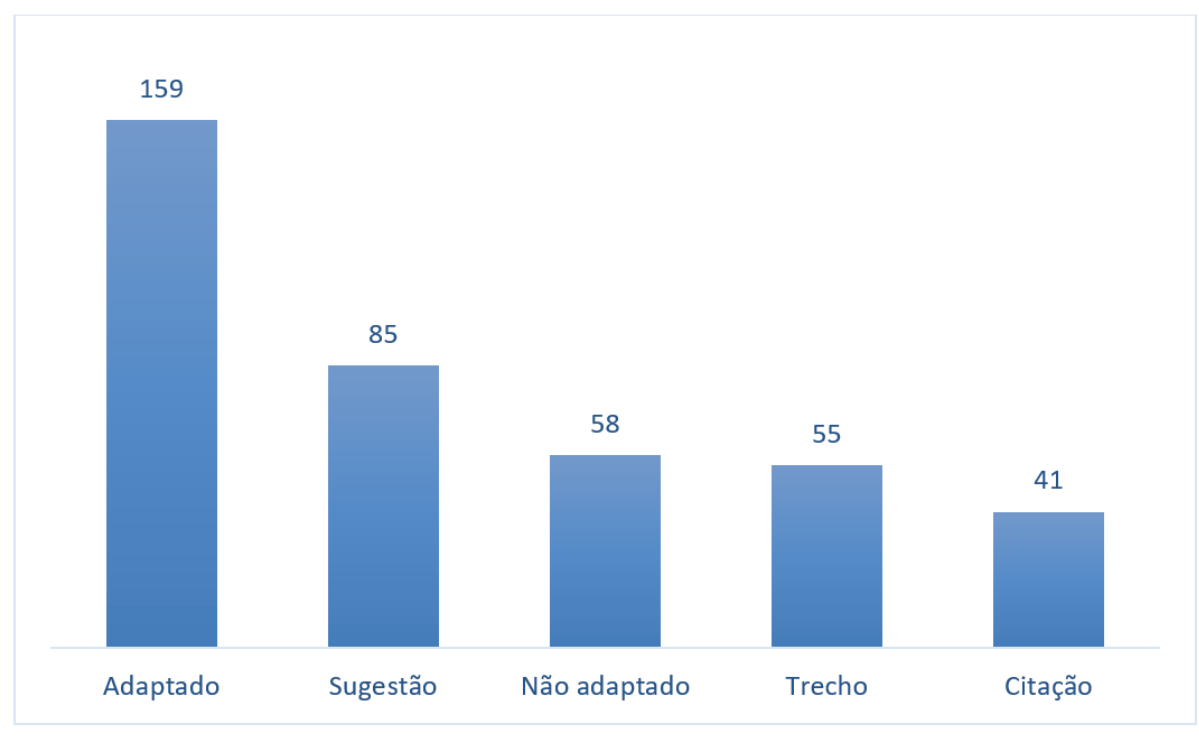

Fonte: autores. 
Estes resultados vão de encontro à análise similar de Martins e Damasceno (2002) em livros didáticos de Ciências, que encontraram maior quantidade de textos de DC com algum tipo de adaptação. Pode-se constatar que os autores optaram por reduzi-los a fim de extrair as principais informações neles contidas e adequar à formatação e ao tamanho do livro didático, pois alguns destes artigos podem ocupar várias páginas das revistas de DC. Contudo, faz-se necessário entender que tipos de modificações foram feitas, pois estas adaptações podem alterar o significado original do texto e distorcer a visão da natureza do trabalho científico, como sugerem os trabalhos de Martins et al. (2001), Nascimento (2005) e Autores X2, que compararam os artigos originais com os inseridos nos livros didáticos.

Algumas coleções didáticas apresentaram recursos visuais acompanhando os textos de DC, totalizando 67 com fotos ou ilustrações, 37 com esquemas, 3 com tabelas e 2 com gráficos. No entanto, existem imagens que foram extraídas de fontes diferentes ou ainda as que não possuem qualquer indicação de suas fontes, podendo ter sido produzidas pelos autores das coleções didáticas.

No que tange às fontes dos textos, a maior parte destes foi retirada de jornais de grande circulação, totalizando 121 ocorrências, com destaque para os jornais Folha de S. Paulo (70 ocorrências) e O Estado de S. Paulo (36 ocorrências). As revistas de DC representam a segunda maior quantidade de textos, totalizando 113 ocorrências, com predominância da revista Ciência Hoje, fonte mais utilizada por todas as coleções didáticas analisadas, com 74 ocorrências. O gráfico 4 resume as principais fontes midiáticas utilizadas pelos autores das coleções didáticas.

\section{Gráfico 4 - Fontes midiáticas das quais os textos de DC foram extraídos.}

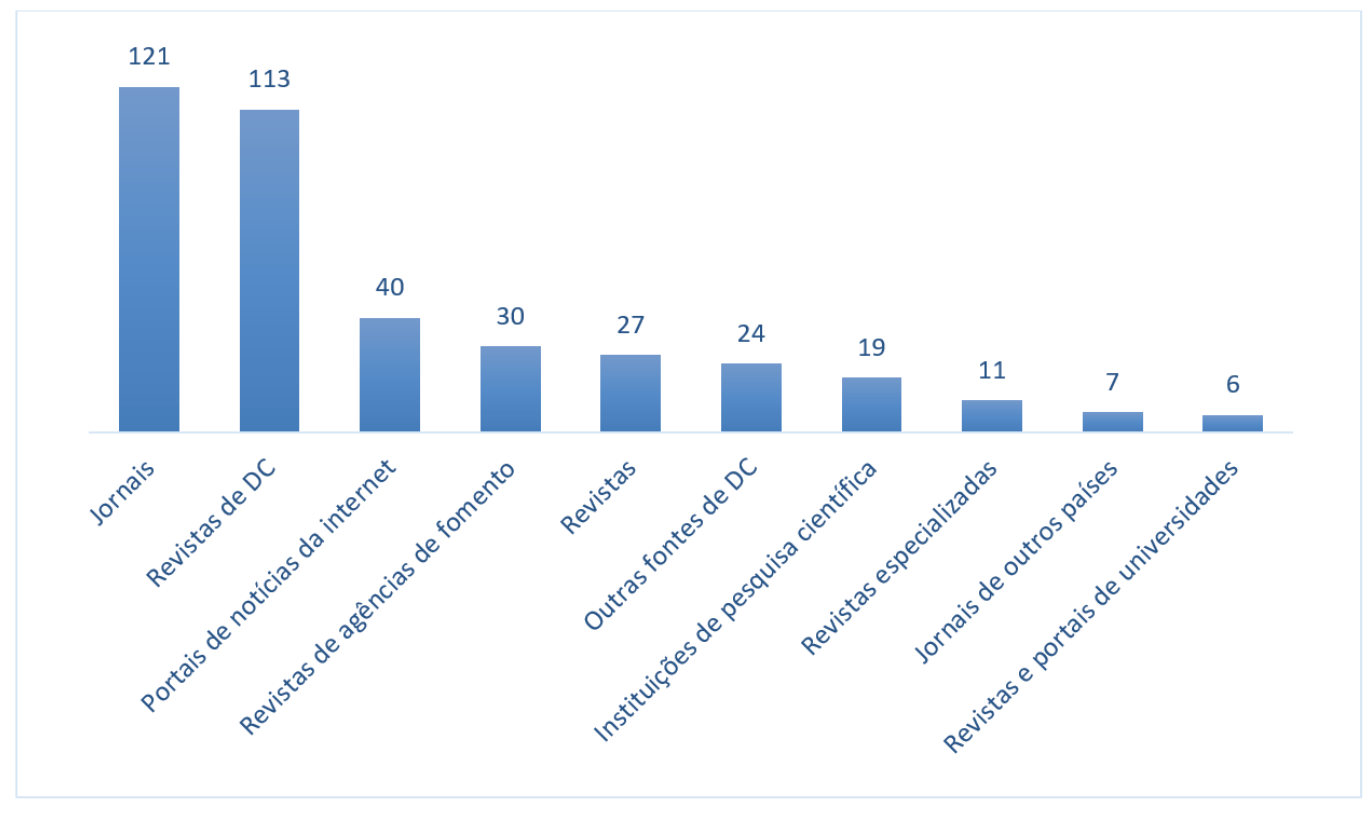

Fonte: autores.

Estes resultados estão de acordo com a pesquisa similar de Martins e Damasceno (2002), que encontraram 83\% de textos provenientes de jornais e revistas especializadas de DC em livros didáticos de Ciências. A opção por estas fontes ressalta a preocupação em obter textos que estejam com uma linguagem mais acessível aos alunos. Estas fontes são tradicionalmente utilizadas por professores que desejam trabalhar com textos de DC em sala de aula e por pesquisadores que investigam as características destes textos, como o discurso ou a acuidade dos conhecimentos científicos, com destaque especial à revista Ciência Hoje (Autores X3). Grande parte das fontes dos artigos veio de endereços eletrônicos, mesmo aqueles provenientes de jornais e revistas, o que facilita ao aluno recorrer ao conteúdo original do artigo caso desenvolva interesse pelo assunto. Também aumenta o espectro do que pode ser considerado como DC, pois estão presentes matérias encontradas em portais de universidades ou instituições de pesquisa, como a Fiocruz, ou até em sites pessoais, como o do doutor Drauzio Varella. 
Os autores dos textos de DC foram classificados em três categorias, de acordo com sua formação acadêmica e ocupação profissional: os jornalistas, os cientistas e os que não se incluem nestas duas categorias, como políticos, economistas e empresários, sendo categorizados como “outros”. Como a maior parte dos autores não apresenta qualquer descrição de sua ocupação profissional, duas fontes de resultados auxiliaram nesta identificação: o portal do currículo Lattes, da Capes, que apresenta a vida profissional e acadêmica dos autores, e os sites das próprias revistas e jornais, que podem fornecer tais informações. Foram encontrados 148 textos escritos por jornalistas, o que pode caracterizar o jornalismo científico como uma forma de especialização profissional; e 95 textos de cientistas, divulgando seus conhecimentos científicos para o público leigo. Nota-se que três textos foram redigidos por autores com as duas formações, o que permite avaliar que há um cuidado em esclarecer os conceitos científicos ali desenvolvidos sem distorcê-los. O gráfico 5 esclarece estes resultados acerca da formação dos autores.

Gráfico 5: Formação profissional e acadêmica dos autores dos textos de DC.

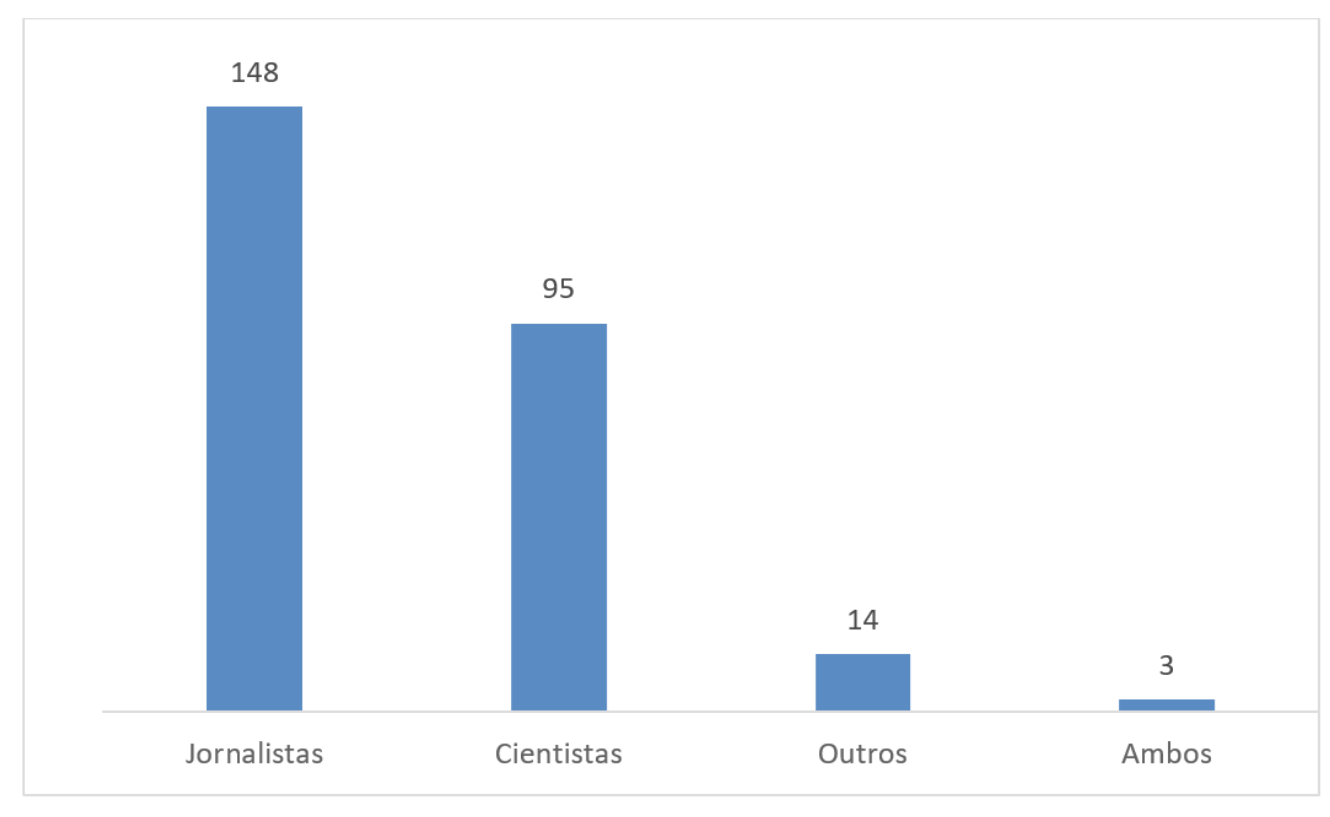

Fonte: autores.

Os livros didáticos selecionaram os artigos pelo conteúdo da reportagem e pela acessibilidade da linguagem, não havendo preferência pelo tipo de autor, com exceção de L05, que apresenta apenas textos escritos por cientistas. É relevante expor que os textos redigidos por cientistas normalmente apresentam dados de suas pesquisas, explicações complementares sobre determinados conceitos científicos ou elucubrações sobre questões morais e éticas internas à ciência.

\section{CONSIDERAÇÕES FINAIS}

Conforme abordado anteriormente, textos de DC podem configurar uma importante estratégia no Ensino de Ciências ao contextualizar os conteúdos desenvolvidos em sala de aula, tornando a aula mais atraente, participativa e dinâmica. No entanto, observa-se que diversos trabalhos acadêmicos que analisam estes materiais esquecem a sua utilização em sala de aula e sua possível interferência no processo de ensino-aprendizagem. Também não promovem metodologias que possam auxiliar os professores na aplicação destes textos com seus alunos. No caso dos livros didáticos, além da leitura dos textos de DC, os autores propõem questões norteadoras que auxiliam a sedimentar as informações lidas, podendo ser uma importante estratégia pedagógica para contextualizar os conhecimentos transmitidos pelo livro com os da DC. Resta identificar se esta problematização sugerida pelas coleções está adequada ao escopo do que é desenvolvido ao longo da unidade didática em questão e se promove conexões relevantes com o conteúdo do texto. 
Por outro lado, a presença de textos de DC em livros didáticos suscita o debate a respeito da utilização dos mesmos em sala de aula, uma vez que são selecionados de acordo com o conteúdo científico abordado e a possibilidade de problematizá-lo e contextualizá-lo e submetidos a processos de reelaboração discursiva, no qual são adaptados para o público leitor (MARTINS et al., 2001; NASCIMENTO, 2005; Autores X2). Desta forma, é possível compreender que fatores interferem nesta seleção e adaptação, entendendo que ocorrem devido não só a sua adequação em relação ao assunto trabalhado ou à série em questão, como também à concepção de ciência dos autores dos livros didáticos. Assim, tais textos podem fornecer um parâmetro relevante a fim de corroborar as intencionalidades didáticas que regem a escolha e a posterior modificação destes materiais de DC, a fim de torna-los efetivamente aptos para o desenvolvimento de práticas pedagógicas.

Com base nestes argumentos, faz-se imprescindível realizar uma comparação entre os textos de DC extraídos diretamente das revistas e jornais com os textos de DC presentes em livros didáticos, entendendo de que maneira um material de DC se torna um material educativo. Para tal, é importante analisar de forma criteriosa não só as características textuais mais superficiais, como linguagem, uso de analogias e metáforas e possíveis inconsistências, como também perceber a visão de Natureza da Ciência de cada texto e identificar que valores éticos, morais, culturais e políticos estão imersos. A Análise de Discurso fornece estrutura metodológica adequada para realizar tal comparação, como sugere Galieta (2013), no sentido de caracterizar que contextos sociais e ideológicos conduzem a maneira como o texto de DC apresenta as pesquisas científicas. Acredita-se que uma pesquisa deste caráter irá contribuir para o entendimento das relações entre DC e o Ensino de Ciências, criando bases que possam guiar os professores na utilização de textos de DC em sala de aula.

\section{REFERÊNCIAS}

AUTHIER, J. La mise en scène de la communication dans des discours de vulgarisation scientifique. Langue Française, n.53, p.34-47, 1982.

BRASIL. Ministério da Educação. Parâmetros Curriculares Nacionais: Terceiro e quarto ciclos do ensino fundamental. Brasília: MEC/SEF, 2000.

BRASIL. Ministério da Educação. Guia de Livros Didáticos: PNLD 2015: Biologia: Ensino Médio. Brasília: MEC/SEB, 2014.

BUENO, W. Comunicação científica e divulgação científica: aproximações e rupturas conceituais. Informação \& Informação, Londrina, vol. 15, n. esp, p. 1-12, 2010.

CAVALCANTE FILHO, U.; TORGA, V.L.M. O plurilinguismo da divulgação científica no livro didático de língua portuguesa. Eutomia - Revista de Literatura e Linguística, Recife, v. 12, n. 1, p. 339-358, 2013.

FERREIRA, L.N.A.; QUEIROZ, S.L. Características discursivas de artigos de divulgação científica relacionados à química. Revista Electrónica de Enseñanza de las Ciencias, v. 11, n. 1, p. 21-42, 2012.

FERREIRA, L.N.A.; QUEIROZ, S.L. Textos de Divulgação Científica no Ensino de Ciências: uma revisão. Alexandria - Revista de Educação em Ciência e Tecnologia, Florianópolis, v. 5, n. 1, p. 3-31, 2012.

GALIETA, T. Análise de Discurso de textos do livro didático e de divulgação científica: caracterizando formações discursivas. In: Encontro Nacional de Pesquisa em Educação em Ciências, 9. Águas de Lindóia, SP, 2013. Atas... Águas de Lindoia: ABRAPEC, 2013.

GOLDBACH, T.; EL-HANI, C.N.; MARTINS, R.C. A difícil tarefa da divulgação da idéia de gene em revistas de divulgação científica no Brasil. In: Reunião da Red POP, 9., Rio de Janeiro, 2005. Atas... Rio de Janeiro: Red POP, 2005. 
GOLDBACH, T.; EL-HANI, C.N. Entre Receitas, Programas e Códigos: Metáforas e Idéias Sobre Genes na Divulgação Científica e no Contexto Escolar. Alexandria - Revista de Educação em Ciência e Tecnologia, Florianópolis, v. 1, n. 1, p. 153-189, 2008.

GOMES, M.C., DA POIAN, A.T.; GOLDBACH, T. Revistas de Divulgação Científica no Ensino de Ciências e Biologia: contribuições e limitações de seu uso. In: Encontro Nacional de Ensino de Ciências da Saúde e do Ambiente (ENECIENCIAS), 3., 2012, Niterói. Anais... Niterói, 2012.

GONÇALVES, E.M. Os discursos da divulgação científica: Um estudo de revistas especializadas em divulgar ciência para o público leigo. Brazilian Journalism Research, São Paulo, v. 9, n. 2, 2013.

GRILLO, S.; DOBRANSZKY, E.; LAPLANE, A. Mídia impressa e educação científica: uma análise das marcas do funcionamento discursivo em três publicações. Cadernos Cedes, Campinas, v. 24, n. 63, p. 215-236, 2004.

KEMPER, A; ZIMMERMANN, E.; GASTAL, M.L. Textos populares de divulgação científica como ferramenta didático pedagógica: o caso da evolução biológica. Revista Brasileira de Pesquisa em Educação em Ciências, São Paulo, v. 10, n. 3, p. 25-50, 2010.

LOUREIRO, José Mauro. Museu de ciência, divulgação científica e hegemonia. Ciência da Informação, Brasília, v. 32, n. 1, p. 88-95, 2003.

MARTINS, I.; CASSAB, M.; ROCHA, M. Análise do processo de re-elaboração discursiva de um texto de divulgação científica para um texto didático. Revista Brasileira de Pesquisa em Educação em Ciências, São Paulo, v. 1, n. 3, p. 1-9, 2001.

MARTINS, I.; DAMASCENO, A. Uma análise das incorporações de textos de divulgação científica em livros didáticos de ciências. In: Encontro de Pesquisa em Ensino de Física, 8., São Paulo, 2002. Atas... São Paulo: SBF, 2002.

MARTINS, I.; NASCIMENTO, T.; ABREU, T. Clonagem na sala de aula: um exemplo de uso didático de um texto de divulgação científica. Investigações em Ensino de Ciências, Porto Alegre, v. 9, n. 1, p. 95-111, 2004.

NASCIMENTO, T.G. O discurso da divulgação científica no livro didático de ciências: características, adaptações e funções de um texto sobre clonagem. Revista Brasileira de Pesquisa em Educação em Ciências, São Paulo, v. 5, n. 2, p. 1-13, 2005.

NASCIMENTO, T.G. Leituras de divulgação científica na formação inicial de professores de ciências. 2008. 376f. Tese (Doutorado em Educação Científica e Tecnológica) - Centro de Ciências da Educação, Universidade Federal de Santa Catarina (UFSC), Florianópolis, 2008.

NASCIMENTO, T.G.; REZENDE-JR., M.F. A produção sobre divulgação científica na área de educação em ciências: referenciais teóricos e principais temáticas. Investigações em Ensino de Ciências, Porto Alegre, v. 15, n.1, p. 97-120, 2010.

ORLANDI, E. Divulgação Científica e efeito leitor: uma política social urbana. In: Discurso e texto. Formulação e circulação dos sentidos. Campinas: Pontes, 2001. p. 149-162.

PUIATI, L.; BOROWSKY, H.; TERRAZZAN, E. O texto de divulgação científica como recurso para o ensino de ciências na educação básica: um levantamento das produções nos ENPEC. In: Encontro Nacional de Pesquisa em Educação em Ciências (ENPEC), 6., Florianópolis, 2007. Anais... Florianópolis: ABRAPEC, 2007.

ROCHA, R.B.S.S. Práticas de escrita: texto de divulgação científica em livro didático de Português. Linha d’Água, São Paulo, v. 2, n. 25, p. 185-201, 2012. 
SILVA, F.V. Didatização da divulgação científica: uma análise de manuais didáticos de Língua Portuguesa do Ensino Médio. E-scrita, Nilópolis, v.4, n. 4, 2013.

ZAMBONI, L.M.S. Cientistas, jornalistas e a divulgação científica: Subjetividade e heterogeneidade no discurso da divulgação científica. Campinas: Autores Associados, 2001.

ZAMBONI, L.M.S. Heterogeneidade e subjetividade no discurso da divulgação científica. 1997. 211f. Tese (Doutorado em Linguística) - Instituto de Estudos da Linguagem, Universidade Estadual de Campinas, Campinas, 1997. 